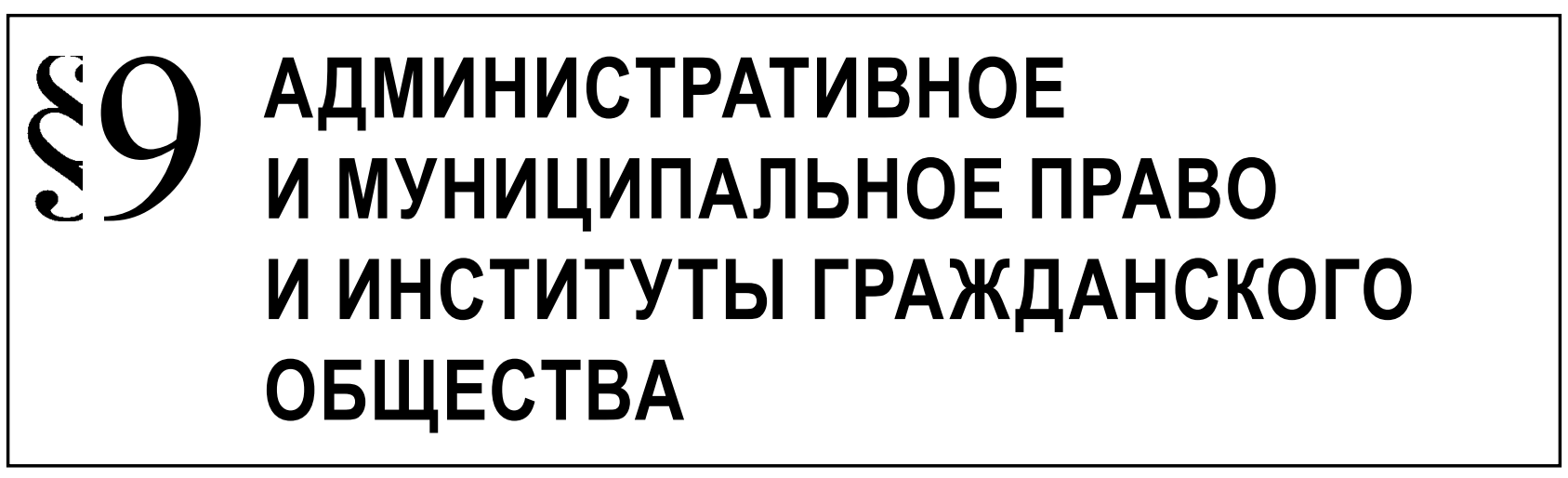

Филатова Е.В.

\title{
СОВЕРШЕНСТВОВАНИЕ МЕХАНИЗМА ЭКСПЕРТИЗЫ НОРМАТИВНЫХ ПРАВОВЫХ АКТОВ, КАСАЮЩИХСЯ РЕГУЛИРОВАНИЯ ОТНОШЕНИЙ В БАНКОВСКОЙ СФЕРЕ
}

\begin{abstract}
Аннотация: Вопросы повышения качества принимаемых нормативных актов является весьма актуальной проблемой для любого из направлений современного законотворчества. Целиком и полностью данное утверждение касается регулирования деятельности отечественных кредитных организаций. Одним из ключевых направлений решения указанной проблемы является совершенствование экспертизы проектов готовящихся к рассмотрению законодательных и нормативных актов. При этом используемые в настоящее время виды исследований проектов нормативных правовых актов относятся исключительно к разновидностям государственных экспертиз. В отношении банковского законодательства, по нашему мнению, их необходимо дополнить таким важным институтом как общественная экспертиза. В представленной статье используется институциональный подход к анализу сущности общественной экспертизы. В его рамках применяются методы сравнительного, структурного и системного анализа. На основе проведенного исследования делается выводо том, что ключевыми институтами, способными квалифицированно осуществлять общественную экспертизу нормативных правовых актов в срере банковского регулирования и их проектов являются Общественная палата РФ и Межрегиональный банковский совет при Совете Федерации РФ. Также автором формулируется комплекс предложений по развитию института общественной экспертизы нормативных правовых актов в срере регулирования отношений в банковской срере.

Ключевые слова: правовая экспертиза, банковское законодательство, общественная экспертиза, Центральный банк, механизм экспертизы, нормативно правовые акты, кредитные институты, субъекты экономической деятельности, законодательное регулирование, качество правовых актов.
\end{abstract}

$\mathrm{O}$ дним из ключевых направлений совершенствования процесса регулирования всего спектра отношений, возникающих в банковской сфере, является, на наш взгляд, более эффективная организация экспертизы действующих нормативных правовых актов, а также проектов вновь принимаемых документов, касающихся различных аспектов функционирования кредитных институтов и механизмов. Во многом это объясняется тем, что деятельность данных институтов напрямую затрагивает интересы как практически всех субъектов экономической деятельности, так и подавляющего большинства граждан государства.
Законодательное регулирование банковской деятельности в качестве своей цели ставит упорядочивание деятельности кредитных организаций, основными задачами которых является удовлетворение собственных экономических потребностей и интересов юридических и физических лиц. При этом специальное банковское законодательство, которое непосредственно направлено на правовое регулирование деятельности в кредитной сфере, включает в себя следующие важнейшие законодательные акты:

1) Федеральный закон от 2 декабря 1990 г. № 395-I «0 банках и банковской деятельности»; 
2) Федеральный закон от 10 июля 2002 г. № 86Ф3 «О Центральном банке Российской Федерации (Банке России)», который определяет ключевые функции и полномочия Центрального Банка, констатируя, что он осуществляет свою деятельность независимо от государственной власти, органов государственной власти субъектов Российской Федерации и органов местного самоуправления.

Также в группу актов специального банковского законодательства входят Федеральный закон от 25 февраля 1999 г. № 40-Ф3 «0 несостоятельности (банкротстве) кредитных организаций» и Федеральный закон от 23 декабря 2003 г. № 177-Ф3 «0 страховании вкладов физических лиц в банках Российской Федерации». Указанные документы определяют специфику банкротства кредитных организаций, а также устанавливают круг особых обязанностей для кредитных организаций, привлекающих вклады физических лиц.

Названные законодательные акты обладают приоритетом в отношении общих норм прочих законодательных актов в вопросах, касающихся регулирования банковской сферы и деятельности кредитных организаций, обусловленный присущим этим документам специальным характером.

При этом действующие нормативные правовые акты, касающиеся регулирования банковской сферы, требуют постоянного совершенствования. Во многом это обуславливается наличием недостаточно проработанных норм, зачастую не согласующихся, а иногда и противоречащих действующему законодательству. Данное обстоятельство свидетельствует о необходимости качественного совершенствования процесса правовой экспертизы вновь принимаемых нормативных правовых актов в банковской сфере.

По мнению В. А. Закоева и А. К. Дзугкоева, экспертизу нормативных правовых актов и их проектов можно определить как исследование, которое осуществляют лица, обладающие специальными познаниями, в целях определения качества правовых актов и проектов правовых актов и прогнозной оценки возможных последствий их реализации и/или принятия. [1, с. 95]

Основная цель правовой экспертизы - разработка и принятие качественных нормативных правовых актов, регулирующих взаимоотношения в банковской сфере, соответствующих Конституции Российской Федерации и российскому законодательству. С точки зрения И. А. Закирова, экспертиза нормативных правовых актов обладает следующими ключевыми признаками: [2, с. 63]
- $\quad$ экспертиза нормативных правовых актов и их проектов представляет собой неотъемлемую составную часть нормотворческого процесса;

- $\quad$ экспертиза правовых актов и их проектов проводится с целью обеспечения соответствия нормативных предписаний общепризнанным принципам и нормам международного права, положениям, содержащимся в Конституции РФ, федеральных конституционных законах, федеральных законах, указах и распоряжениях Президента РФ, а также действующих ведомственных нормативных правовых актах;

- в процессе экспертизы нормативных правовых актов и их проектов устраняются имеющиеся нормотворческие ошибки различного характера и определяются пути устранения данных ошибок;

- $\quad$ предметом экспертизы нормативных правовых актов и их проектов является конкретный документ в единстве его текста, структуры и формы;

- последствием ошибок, допущенных при проведении экспертизы нормативных правовых актов и их проектов, выступает дефектность правовых актов и выступающие ее следствием бюрократизация права, нормативная конфликтность и моральная устарелость правовых норм, отсутствие стабильности системы правового регулирования, неэффективное применение правовых актов и коррупциогенность норм. содержащихся в них;

- $\quad$ экспертиза нормативных правовых актов и их проектов производится перед представлением данных документов в полномочный орган либо на подпись должностному лицу.

Говоря об особенностях правовой экспертизы в банковской сфере, отметим, что формы данной экспертизы можно классифицировать по нескольким основаниям:

1. По объекту - экспертиза действующих правовых актов, экспертиза законопроектов, экспертиза подзаконных актов ЦБ РФ.

2. По субъекту - внутренняя, внешняя, общественная.

3. По содержанию - на соответствие Конституции, на соответствии действующему законодательству, по оценке финансовых последствий принятия нормативного акта, антикоррупционная. Что касается механизма экспертизы нормативных правовых актов и их проектов, то отметим, что при принятии законодательных актов, касающихся регулирования деятельности кредитных организаций, Правовое управление Аппарата Государ- 
ственной Думы осуществляет правовую экспертизу законопроекта, т.е. проверку законопроекта на соответствие Конституции, федеральным конституционным законам, федеральным законам, основным отраслевым законодательным актам.

Разновидностью правовой экспертизы является независимая экспертиза поправок к законопроекту, которую вправе проводить ответственный комитет. Кроме того, производятся юридико-техническая и лингвистическая экспертизы, которые также осуществляются Правовым управлением Аппарата Государственной Думы.

Кроме того, могут осуществляться экономическая и финансовая экспертизы, разрешающие вопрос об оправданности, эффективности и исполнимости предлагаемых законопроектом мер в финансово-экономическом аспекте. [3, с. 31]

При этом отметим, что проведение правовой экспертизы в сфере банковского законодательства требует использования специальных знаний экспертов, то есть знаний, которые они приобрели в процессе своей практической деятельности путем специальной подготовки или профессионального опыта и которые, базируются на системе теоретических знаний в определенной сфере. [4, с. 399] В этой связи при подготовке законопроектов, связанных с регулированием банковской деятельности, активно используется опыт специалистов Центрального Банка Российской Федерации.

В числе главных направлений деятельности специалистов Юридического департамента ЦБ РФ можно отметить их участие в процессе разработки проектов федеральных законов, непосредственно затрагивающих компетенцию Банка России. Все основополагающие для отрасли банковского права законодательные акты был приняты после тщательной работы экспертов Банка России. В первую очередь, это касается федеральныхзаконов «0 Центральном банке Российской Федерации (Банке России)», «0 банках и банковской деятельности», «0 несостоятельности (банкротстве) кредитных организаций», «0 страховании вкладов физических лиц в банках Российской Федерации», «0 рынке ценных бумаг», «0 валютном регулировании и валютном контроле», «0 противодействии легализации (отмыванию) доходов, полученных преступным путем, и финансированию терроризма».

Работники Юридического департамента ЦБ РФ непосредственно участвуют в подготовке новых законопроектов, производя их правовую и юридико-лингвистическую экспертизу. О степени успешности данной деятельности свидетельствует неоднократная высокая оценка Министерством юстиции РФ уровня юридической подготовки нор- мативных актов Банка России, в его докладах Президенту Российской Федерации. [5, с. 30]

В настоящее время все большее внимание при подготовке нормативных правовых актов в банковской сфере уделяется проведению их антикоррупционной экспертизы. При этом факторы коррупциогенности, которым уделяется основное внимание при проведении данной экспертизы, приведены в таблице 1 .

В целях выявления указанных в таблице 1 факторов в проектах нормативных правовых актов Центрального Банка РФ был принят Приказ № ОД-633 «Об организации работы по проведению антикоррупционной экспертизы нормативных актов Банка России и их проектов» от 1 октября 2009 года. В соответствие с данным документом предписано организовать проведение антикоррупционной экспертизы разработанных структурными подразделениями Банка России проектов нормативных актов ЦБ РФ перед их передачей на согласование. При этом оформление результатов антикоррупционной экспертизы предусматривается путем принятия заключения об ее проведении, подписываемом руководителем структурного подразделения или его заместителем. Необходимо указать на то, что заключение ответственного структурного подразделения по результатам антикоррупционной экспертизы не составляется в отношении проектов нормативных актов ЦБ РФ, касающихся установления (изменения) величины процентных ставок, величины платы за право пользования внутридневными кредитами и нормативов обязательных резервов (резервных требований) ЦБ РФ.

Отметим, что указанные виды исследований проектов нормативных правовых актов относятся к разновидностям государственных экспертиз. В отношении банковского законодательства их необходимо дополнить таким важным институтом системы общественного контроля как общественная экспертиза. Отметим, что, несмотря на то, что она упоминается в значительном числе нормативных правовых актов, законодательное определение общественной экспертизы в российском праве к настоящему моменту отсутствует. Кроме того, ни в одном из законодательных актов федерального уровня нет указания на круг субъектов и объектов общественной экспертизы, ее виды, соотношение с государственной и гражданской экспертизой и т.д. При этом определенные наработки в этой области имеются в законодательных актах субъектов Федерации. [3, с. 33]

Ключевым институтом, способным квалифицированно осуществлять экспертизу нормативных правовых актов в сфере банковского регулирова- 


\section{Факторы коррупциогенности, подлежащие выявлению \\ при проведении антикоррупционной экспертизы [6]}

\begin{tabular}{|c|c|}
\hline $\begin{array}{c}\text { Фактор } \\
\text { коррупциогенности }\end{array}$ & Критерии коррупциогенности \\
\hline $\begin{array}{l}\text { Широта административ- } \\
\text { ного усмотрения }\end{array}$ & $\begin{array}{l}\text { •отсутствие строго определенных сроков (широкие временные интервалы) осуществления } \\
\text { отдельных действий (принятия определенных решений); } \\
\text { •отсутствие условий принятия одного из нескольких возможных решений, затрагивающих } \\
\text { права и свободы граждан, интересы юридических лиц; } \\
\text { •содержание норм, неоднозначно или не исчерпывающим образом определяющих условия } \\
\text { принятии решения; } \\
\text {-определение компетенции по фрормуле «вправе»; } \\
\text {-произвольность выбора норм, подлежащих применению. }\end{array}$ \\
\hline $\begin{array}{l}\text { Несовершенство юриди- } \\
\text { ческой техники }\end{array}$ & $\begin{array}{l}\text { •использование двусмысленных или неустоявшихся терминов, понятий и формулировок, ка- } \\
\text { тегорий оценочного характера, с неясным, неопределенным содержанием, не используемых } \\
\text { российским законодательством, допускающих различные трактовки, обозначение одних и тех } \\
\text { же явлений различными терминами; } \\
\text { •выбор федерального закона, примененного при принятии правового акта, не подлежащего } \\
\text { применению. }\end{array}$ \\
\hline \begin{tabular}{|l|} 
Дублирование функций \\
и полномочий органов \\
государственной власти \\
/ Избыточное государ- \\
Ственное регулирование \\
\end{tabular} & $\begin{array}{l}\text { •дублирующие полномочия разных государственных служащих в рамках одного государ- } \\
\text { ственного органа или различных государственных органов } \\
\text { •наличие норм, устанавливающих ответственность нескольких государственных служащих за } \\
\text { одно и то же решение. }\end{array}$ \\
\hline $\begin{array}{l}\text { Информационная за- } \\
\text { крытость }\end{array}$ & $\begin{array}{l}\text { •наличие в нормативном правовом акте положений, ограничивающих доступ к информации о } \\
\text { деятельности государственных органов; } \\
\text { •неконкретность норм, регулирующих отношения по поводу такой информации; } \\
\text { •отсутствие норм об отчетности органа или его должностных лиц перед обществом либо } \\
\text { соответствующими просрессиональными и иными сообществами. }\end{array}$ \\
\hline $\begin{array}{l}\text { Бюрократизация } \\
\text { административных } \\
\text { процедур }\end{array}$ & $\begin{array}{l}\text { обреме- } \\
\text { ти; }\end{array}$ \\
\hline Пробельность права & $\begin{array}{l}\text { •наличие норм, отсылающих к положениям актов органов, неполномочных регулировать } \\
\text { конкретное общественное отношение; } \\
\text { •наличие норм, отсылающих к еще не принятым нормам, не вступившим в законную силу, } \\
\text { или утратившим силу. }\end{array}$ \\
\hline Коллизия в праве & $\begin{array}{l}\text { •противоречие норм одного или разных уровней законодательства, затрагивающих права и } \\
\text { законные интересы физических лиц и организаций; } \\
\text { •наличие противоречий в отдельной норме нормативных правовых актов (либо противоречие } \\
\text { нормативных правовых актов другому акту), позволяющих различное толкование нормы; } \\
\text { •наличие норм, отсылающих к положениям актов органов, неполномочных регулировать } \\
\text { конкретное общественное отношение. }\end{array}$ \\
\hline $\begin{array}{l}\text { Нарушение баланса } \\
\text { интересов }\end{array}$ & $\begin{array}{l}\text { •наличие положений нормативных правовых актов, анализ которых свидетельствует о том, что в } \\
\text { результате его принятия «выигрывает» только одна группа субъектов гражданского права. }\end{array}$ \\
\hline $\begin{array}{l}\text { Нарушение процедуры } \\
\text { принятия нормативных } \\
\text { правовых актов }\end{array}$ & $\begin{array}{l}\text { •нарушение сроков принятия акта; } \\
\text { •нарушение порядка опубликования акта; } \\
\text {-отсутствие компетенции органа государственной власти (лица) на принятие акта, либо из- } \\
\text { дание с превышением полномочий, предоставленных данному органу; } \\
\text { •принятие правового акта во исполнение отмененного федерального закона. }\end{array}$ \\
\hline
\end{tabular}

ния и их проектов, по нашему мнению, является Общественная палата РФ. Во многом это обусловлено тем, что основные параметры общественной экспертизы законопроектов и нормативных правовых актов определены в ст. 18 и 19 Федерального закона № 32-Ф3 «Об Общественной палате Российской Федерации» от 4 апреля 2005 года.

При этом отметим, что первые предпосылки к задействованию потенциала Общественной палаты в области экспертизы проектов нормативных правовых актов в банковской сфере уже появились.
В частности, в соответствие с подготовленным в 2013 году законопроектом действующее законодательство предлагается дополнить положениями, которые позволят Общественной палате взаимодействовать с Центральным банком РФ. В частности, Общественная палата получит возможность приглашать к себе уполномоченных сотрудников ЦБ для консультаций и пояснений, направлять в ЦБ запросы и обращения, а Банк России будет обязан проинформировать Общественную палату о результатах рассмотрения обращений. [7] 
При проведении общественной экспертизы нормативных правовых актов, относящихся к регулированию банковской сферы, которая может осуществляться соответствующими комитетами Общественной палаты РФ, как мы уже отмечали, целесообразно привлечение экспертов, обладающих совокупностью специальных знаний.

В этой связи весьма полезным, по нашему мнению, представляется использование экспертных возможностей Межрегионального банковского совета при Совете Федерации РФ. Данный Совет представляет собой действующий консультативный орган при Совете Федерации Федерального Собрания РФ, созданный с целью налаживания сотрудничества Совета Федерации с организациями банковской системы в целях совершенствования банковского законодательства, оказания экспертной и общественно-политической поддержки развитию банковской системы в субъектах РФ. К основным задачам данного Совета относятся:

1) изучение состояния национального банковского законодательства и перспектив его совершенствования;

2) подготовка предложений органам, уполномоченным осуществлять регулирование банковской деятельности, направленных на совершенствование государственной политики в области развития банковской системы;

3) выработка рекомендаций и предложений по формированию и реализации государственной политики в банковской сфере;

4) подготовка предложений и проектов документов по вопросам обеспечения банковской безопасности, в том числе, предложений по внесению изменений в действующие нормативные правовые акты;

5) разработка предложений по совершенствованию правовых и экономических условий работы кредитных организаций в субъектах РФ.

В качестве примера экспертной деятельности Межрегионального банковского совета можно привести рекомендации, принятые 4 апреля 2014 года на заседании Совета при рассмотрении проекта Федерального закона «О внесении изменений в Федеральный закон «0 несостоятельности (банкротстве)» и отдельные законодательные акты Российской Федерации в части регулирования реабилитационных процедур, применяемых в отношении гражданина-должника»: [8]

- повысить минимальный порог задолженности для начала процедуры банкротства индивидуальных предпринимателей и физических лиц до 300 тыс. руб. (в законопроекте предполагается порог в 50 тыс. руб.);

- установить обязательность института финансового управляющего в случае банкротства физического лица (в законопроекте финансовый управляющий утверждается арбитражным судом по ходатайству лиц, участвующих в деле о банкротстве);

- определить состав и порядок включения сведений, подлежащих включению в Единый федеральный реестр сведений о банкротстве;

- уточнить порядок обращения взыскания на жилое помещение (предлагается установить, что если жилье явно превышает по своим характеристикам (площади, конструктивным особенностям, рыночной стоимости и т.д.) указанный уровень, то оно подлежит реализации с последующим приобретением для должника иного пригодного для проживания помещения);

- установить возможность временного ограничения прав должника, в отношении которого введена реструктуризация долгов, а также должника, признанного банкротом;

- уточнить критерии сделок, которые могут быть оспорены в рамках дела о банкротстве должника, и установить сроки рассмотрения требований кредиторов;

- у уточнить процедуры участия кредитора в процессе реструктуризации долга гражданинабанкрота;

- $\quad$ законодательно закрепить обязательную досудебную процедуру урегулирования задолженности гражданина перед кредиторами (в законопроекте она отсутствует);

- повысить ответственность оценщиков за качество предоставляемых услуг по оценке залогового обеспечения (законопроект не содержит норм об ответственности оценщиков);

- принять меры по снижению уровня «криминальных банкротств» (установить уголовную ответственность руководителей организаций за фальсификацию отчетности и бухгалтерских документов, а также собственников и менеджмента за доведение до банкротства организации и непринятие своевременных мер).

Как мы можем отметить, данный законопроект напрямую затрагивает права и интересы граждан и напрямую относится к категории документов, общественную экспертизу которых проводит Общественная палата Российской Федерации, что обуславливает наличие необходимой основы для 
сотрудничества Общественной палаты и Межбанковского экспертного совета.

При этом негативным фактором является то, что, если в процессе подготовки законодательных актов, имеющих отношение к функционированию банковской сферы, потенциал данного Совета в определенной, хотя и в недостаточной, степени используется (заседания проходят всего несколько раз в год), то в отношении нормативных актов министерств и ведомств он своих заключений не представляет. В то же время, Общественная палата РФ обладает подобным правом.

Таким образом, форму общественной экспертизы в отношении нормативных правовых актов, относящихся к регулированию банковского законодательства, необходимо развивать на качественно новой основе, так как она органично дополняет используемые в настоящее время виды государственных экспертиз нормативных правовых актов и их проектов, относящихся к рассматриваемой сфере деятельности. В этой связи, наиболее важными, по нашему мнению, направлениями развития института общественной экспертизы нормативных правовых актов в сфере регулирования отношений в банковской сфере и их проектов являются:

1) законодательное определение института общественной экспертизы в российском праве;

2) определение критериев проектов нормативных правовых актов, регулирующих отношения в банковской сфере, в соответствии с которыми они направляются в органы, осуществляющие общественную экспертизу;

3) закрепление в статусе субъектов общественной экспертизы нормативных правовых актов, имеющих отношение к банковской сфере, Межбанковского экспертного совета и Национального банковского совета.

Реализация предложенных мероприятий, направленных на развитие общественной экспертизы, по нашему мнению, позволит качественно улучшить принимаемые нормативные правовые акты в области юридического регулирования отношений в банковской сфере, как с точки зрения их соответствия действующим правовым нормам, так и с позиции учета общественных интересов, касающихся организации эффективной системы кредитных отношений в стране.

\section{Библиография:}

1. Закоев В. А., Дзугкоев А. К. Понятие правовой экспертизы нормативных правовых актов в МЧС России // Вестник Санкт-Петербургского университета ГПС МЧС России. 2011. № 4. С. 92-97.

2. Закиров И. А. Классификация правовых экспертиз // Следователь. 2008. № 4. С. 61-64

3. Кучерена А. Г. Общественная экспертиза нормативных правовых актов и участие общественных палат в законодательном процессе // Право и жизнь. 2013. № 5. С. 25-40.

4. Криминалистика / под ред. Р. С. Белкина. М. : Норма, 2003.

5. Александрова Т. И., Шаталина Л. В. К 15-летию Юридической службы Банка России // Деньги и кредит. 2007. № 5 . С. 29-32.

6. Методика проведения экспертизы нормативных правовых актов и проектов нормативных правовых актов на коррупциогенность [Электронный ресурс] // Экспертный совет по проведению юридических экспертиз нормативных правовых актов на коррупциогенность при Торгово-промышленной палате Саратовской области. URL: http://anticorr.sartpp.ru/doc's/method.pdf.

7. Общественная палата РФ сможет контролировать пенсионные накопления, направляя запросы в ЦБ [Электронный ресурс] // Информационное телеграфное агентство России. URL: http://itar-tass.com/obschestvo/570293.

8. Межрегиональный банковский совет при Совете Федерации обсудил проект закона о банкротстве физических лиц [Электронный ресурс] // ГАРАНТ.РУ. Информационно-правовой портал. URL: http://www.garant.ru/news/535690.

\section{References (transliterated):}

1. Zakoev V. A., Dzugkoev A. K. Ponyatie pravovoi ekspertizy normativnykh pravovykh aktov v MChS Rossii // Vestnik SanktPeterburgskogo universiteta GPS MChS Rossii. 2011. № 4. S. 92-97.

2. Zakirov I. A. Klassifikatsiya pravovykh ekspertiz // Sledovatel'. 2008. № 4. S. 61-64

3. Kucherena A. G. Obshchestvennaya ekspertiza normativnykh pravovykh aktov i uchastie obshchestvennykh palat $\mathrm{v}$ zakonodatel'nom protsesse // Pravo i zhizn'. 2013. № 5. S. 25-40.

4. $\quad$ Kriminalistika / pod red. R. S. Belkina. M. : Norma, 2003.

5. Aleksandrova T. I., Shatalina L. V. K 15-letiyu Yuridicheskoi sluzhby Banka Rossii // Den'gi i kredit. 2007. № 5. S. $29-32$.

6. Metodika provedeniya ekspertizy normativnykh pravovykh aktov i proektov normativnykh pravovykh aktov na korruptsiogennost' [Elektronnyi resurs] // Ekspertnyi sovet po provedeniyu yuridicheskikh ekspertiz normativnykh pravovykh aktov na korruptsiogennost' pri Torgovo-promyshlennoi palate Saratovskoi oblasti. URL: http://anticorr. sartpp.ru/doc's/method.pdf.

7. Obshchestvennaya palata RF smozhet kontrolirovat' pensionnye nakopleniya, napravlyaya zaprosy v TsB [Elektronnyi resurs] // Informatsionnoe telegrafnoe agentstvo Rossii. URL: http://itar-tass.com/obschestvo/570293.

8. Mezhregional'nyi bankovskii sovet pri Sovete Federatsii obsudil proekt zakona o bankrotstve fizicheskikh lits [Elektronnyi resurs] // GARANT.RU. Informatsionno-pravovoi portal. URL: http://www.garant.ru/news/535690. 